\title{
Size Control of Iron Oxide Nanoparticles Using Reverse Microemulsion Method: Morphology, Reduction, and Catalytic Activity in CO Hydrogenation
}

\author{
Mohammad Reza Housaindokht and Ali Nakhaei Pour \\ Department of Chemistry, Ferdowsi University of Mashhad, P.O. Box 9177948974, Mashhad, Iran \\ Correspondence should be addressed to Ali Nakhaei Pour; nakhaeipoura@yahoo.com
}

Received 8 May 2013; Revised 15 August 2013; Accepted 6 September 2013

Academic Editor: Mohamed Afzal Pasha

Copyright (C) 2013 M. R. Housaindokht and A. Nakhaei Pour. This is an open access article distributed under the Creative Commons Attribution License, which permits unrestricted use, distribution, and reproduction in any medium, provided the original work is properly cited.

\begin{abstract}
Iron oxide nanoparticles were prepared by microemulsion method and evaluated in Fischer-Tropsch synthesis. The precipitation process was performed in a single-phase microemulsion operating region. Different HLB values of surfactant were prepared by mixing of sodium dodecyl sulfate (SDS) and Triton X-100. Transmission electron microscopy (TEM), surface area, pore volume, average pore diameter, pore size distribution, and XRD patterns were used to analyze size distribution, shape, and structure of precipitated hematite nanoparticles. Furthermore, temperature programmed reduction (TPR) and catalytic activity in CO hydrogenation were implemented to assess the performance of the samples. It was found that methane and $\mathrm{CO}_{2}$ selectivity and also the syngas conversion increased as the HLB value of surfactant decreased. In addition, the selectivity to heavy hydrocarbons and chain growth probability $(\alpha)$ decreased by decreasing the catalyst crystal size.
\end{abstract}

\section{Introduction}

Nanoscale materials exhibited novel properties including quantum size effect on photochemistry, nonlinear optical properties of semiconductor and new catalytic properties of metallic nanoparticles [1]. Therefore, synthesis of nanoparticles is of a great interest field during the past few years. As compared to their bulk counterparts, nanoparticles often have superior or even new catalytic properties following from their nanometer size [2]. Hence, the size of the nanoparticles is pivotal in determining the catalytic properties and understanding how size may affect the catalytic properties remains a central goal in nanocatalysis research [3].

Many methods have been reported for preparation of nanoparticles $[2,3]$. Preparation of metallic nanoparticles using microemulsion has been well established [4-7]. Due to the specific structure of the microemulsion system, it was expected as a suitable environment for producing small metal nanoparticles with narrow size distribution. A microemulsion is defined as a system of water, oil, and amphiphile (surfactant) [4-7]. In some respects, microemulsions can be considered as small-scale versions of emulsions, that is, droplet type dispersions either of oil-in-water $(\mathrm{o} / \mathrm{w})$ or of water-in-oil (w/o), with a size range in the order of 5-50 nm in drop radius. In the hydrophilic interior of these droplets, a certain amount of water-soluble material can be dissolved, for example, transition metal salts that then serve as precursor(s) for the final metal particles. As for simple aqueous systems, microemulsion formation is dependent on surfactant type and structure. A surfactant substance reduces the surface tension of a liquid in which it is dissolved [4-7]. Hydrophiliclipophilic balance (HLB) is an important concept which relates the molecular structure to the interfacial packing and film curvature. It is generally expressed as an empirical equation based on the relative proportions of hydrophobic and hydrophilic groups within the molecule. If the structure of the surfactant molecule is designed precisely, the surfactant film may spontaneously adopt a natural radius of curvature of the interface, which has a direction and magnitude without any need for an energy input [4-7].

Recent studies revealed structure sensitive properties of many catalytic reactions like $\mathrm{CO}$ hydrogenation process in 
Fischer-Tropsch synthesis (FTS) [8-12]. Murzin reported that FTS reactions on the supported cobalt based catalysts show many sensitivities to the catalyst particle size $[13,14]$. Moreover, many new results showed that nanosized iron particles play an essential role to achieve high FTS activity [812]. Iron-based catalysts are preferred for utilizing synthesis gas derived from coal or biomass because of the excellent activity for the water-gas-shift reaction, which allows using a synthesis gas with a low $\mathrm{H}_{2} / \mathrm{CO}$ ratio directly without an upstream shift-step $[15,16]$. In our previous works, we tried to show structure sensitivity of unsupported iron catalysts $[10,11,17]$.

In this the present work, feasibility of iron nanoparticle formation in the microemulsion systems with different HLB values was investigated. Moreover, effects of HLB values on the particle size were investigated. Then, catalyst characterization and catalytic FTS reaction are examined at different particle sizes.

\section{Experimental}

2.1. Catalyst Preparation. Fe-Cu nanoparticles were prepared by coprecipitation in a water-in-oil microemulsion [1115]. The precipitation was performed in the single-phase microemulsion operating region. For this purpose, a water solution of metal precursor, $\mathrm{Fe}\left(\mathrm{NO}_{3}\right)_{3}-9 \mathrm{H}_{2} \mathrm{O}$ (Fluka puriss, p.a. ACS: $98-100 \%$ ), and $\mathrm{Cu}\left(\mathrm{NO}_{3}\right)_{2}-4 \mathrm{H}_{2} \mathrm{O}$ (Fluka, purum, p.a. > 97\%) were added to a mixture of an oil phase (Chloroform, Aldrich, >99\%) and mixed surfactants contain Triton X-100 and SDS. The HLB values of Triton X-100 and SDS are 13.4 and 40, respectively. Besides, 1-butanol as a cosurfactant was added to system in order to obtain a proper microemulsion.

For preparation of various sizes of hematite nanoparticles, reverse microemulsions were prepared with different HLB values through varying the weight ratio of Triton $\mathrm{X}-100$ and SDS. For a quaternary system of surfactant $(S, \mathrm{~g})$, oil $(O, \mathrm{~g})$, alcohol $(A, \mathrm{~g})$, and water $(W, \mathrm{~g})$, the following symbols were defined; $\alpha$ represents the mass fraction of oil in water plus oil, $\alpha=O /(W+O), \beta$ the mass ratio of surfactant in the whole system, $\beta=S /(W+O+S+A)$, and $\varepsilon$ the mass fraction of alcohol in the whole system, $\varepsilon=A /(W+O+S+A)$ [4-7]. In the prepared microemulsion system, the parameters are, $\alpha=0.62, \beta=0.03$, and $\varepsilon=0.28$. After stirring well and stabilizing for $24 \mathrm{~h}$, a transparent mixture was obtained. Then, hydrazine was added to reduce metal precursor. The resulting mixture was decanted overnight. The solid was recovered by centrifuging and then washing thoroughly with distilled water and ethanol for several times. Lanthanum promoter was added by wet impregnation method with $\mathrm{La}\left(\mathrm{NO}_{3}\right)_{3}$ precursor on its optimal value after treatment in air as described previously $[10-12,17]$. The promoted catalysts were dried at $383 \mathrm{~K}$ for $16 \mathrm{~h}$ and calcined at $723 \mathrm{~K}$ for $3 \mathrm{~h}$ in air. The catalyst compositions were designated in terms of the atomic ratios as $100 \mathrm{Fe} / 5.64 \mathrm{Cu} / 2 \mathrm{La}$.

2.2. Catalyst Characterization. Elemental analysis was performed to determine the composition of the elements in the bulk of catalysts. The surface area was calculated from the Brunauer-Emmett-Teller (BET) equation and pore volume, average pore diameter, and pore size distribution of the catalysts were determined by $\mathrm{N}_{2}$ physisorption using a micromeritics ASAP 2010 automated system. A $0.5 \mathrm{~g}$ catalyst sample was degassed in the micromeritics ASAP 2010 at $100^{\circ} \mathrm{C}$ for $1 \mathrm{~h}$ and then at $573 \mathrm{~K}$ for $2 \mathrm{~h}$ prior to analysis. The analysis was done using $\mathrm{N}_{2}$ adsorption at $77 \mathrm{~K}$. Both the pore volume and the average pore diameter were calculated by Barrett-Joyner-Hallender (BJH) method from the adsorption isotherm. Assuming that the $\mathrm{Fe}_{2} \mathrm{O}_{3}$ particles are spherical, the corresponding particle size $\left(d_{\mathrm{BET}}\right)$ can be estimated as [18]

$$
d_{\mathrm{BET}}=\frac{6}{\rho A},
$$

where $\rho$ is the true density of $\mathrm{Fe}_{2} \mathrm{O}_{3}$, that is, $5.24 \mathrm{~g} / \mathrm{cm}^{3}$, and $A$ is the specific surface area of samples.

The XRD spectrum of the catalysts was collected by an X-ray diffractometer, Philips PW1840 X-ray diffractometer, using monochromatized $\mathrm{Cu} / \mathrm{K}_{\alpha}$ radiation $(40 \mathrm{kV}, 40 \mathrm{~mA})$, and a step scan mode at a scan rate of $0.02^{\circ}(2 \theta)$ per second from $10-80^{\circ}$. XRD peak identification was recognized by comparison to the JCPDS database software. The average crystallite size of samples, $d_{\mathrm{XRD}}$, can be estimated from XRD patterns by applying full-width half-maximum (FWHM) of characteristic peak (104) $\mathrm{Fe}_{2} \mathrm{O}_{3}$ located at $2 \theta=33.3^{\circ}$ peak to Scherrer equation:

$$
d_{\mathrm{XRD}}=\frac{0.9 \lambda}{\mathrm{FWHM} \cos \theta},
$$

where $\lambda$ is the $\mathrm{X}$-ray wavelength ( $1.5406 \AA$ in this study) and $\theta$ is the diffraction angle for the (104) plane.

Temperature programmed reduction (TPR) measurements of the calcined catalysts were recorded by using a Micromeritics TPD-TPR 2900 system. The catalyst samples (50 mg) were purged with argon at 473 for $30 \mathrm{~min}$ and cooled to $323 \mathrm{~K}$. The samples were heated from 350 to $1100 \mathrm{~K}$ at a rate of $10 \mathrm{~K} / \mathrm{min}$ under flow of $5.1 \%$ hydrogen in argon gas mixture. The consumption of hydrogen was monitored by a thermal conductivity detector (TCD).

The morphology of prepared catalysts was observed with a transmission electron microscope (TEM, LEO $912 \mathrm{AB}$, Germany). An appropriate amount of $\mathrm{Fe}_{2} \mathrm{O}_{3}$ suspension directly taken from the reaction solution was dropped onto the carbon-coated copper grids for TEM observation. The average particle size $\left(d_{\text {TEM }}\right)$ and particle size distribution were determined by TEM images considering more than 100 particles.

2.3. Catalytic Performance. The catalysts were tested in a fixed-bed microreactor. A detailed description of the experimental setup and procedures has been provided elsewhere $[15,16]$. The catalyst samples (3.0 g catalyst diluted with $12 \mathrm{~g}$ quartz, $100-180 \mu \mathrm{m})$ were activated by a $5 \%(\mathrm{v} / \mathrm{v}) \mathrm{H}_{2} / \mathrm{N}_{2}$ gas mixture with space velocity of $15.1 \mathrm{nl} \cdot \mathrm{h}^{-1} \cdot \mathrm{g}_{\mathrm{Fe}}{ }^{-1}$ at $0.1 \mathrm{MPa}$ by increasing temperature from ambient to $673 \mathrm{~K}$ at $5 \mathrm{~K} / \mathrm{min}$, then maintained for one hour, and subsequently 


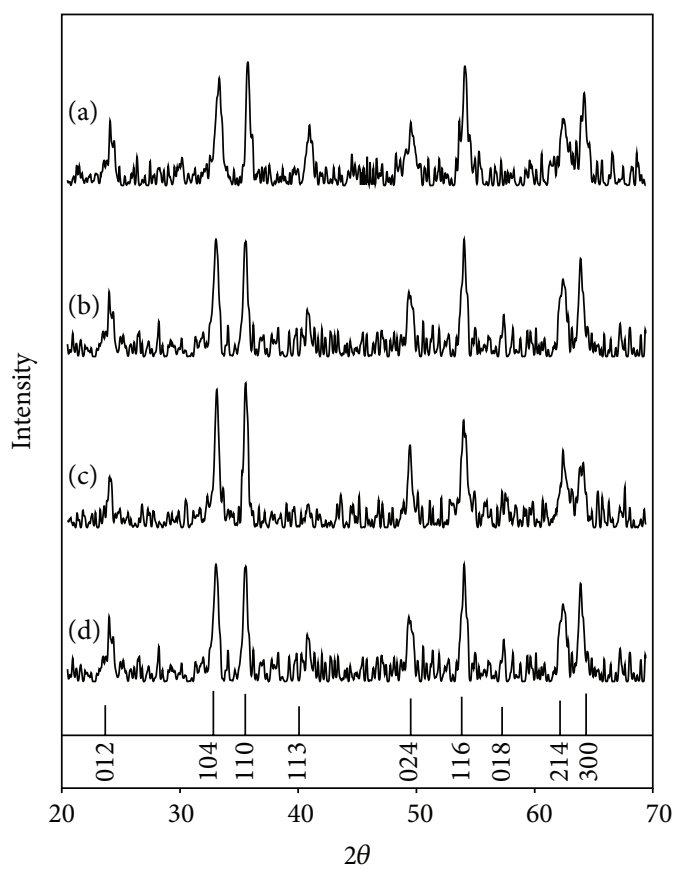

FIGURE 1: X-ray diffraction patterns of the prepared catalysts after calcinations ( (a) HLB $=13.9$, (b) HLB $=23.7$, (c) HLB $=31.2$, and (d) HLB $=40)$.

reduced to $543 \mathrm{~K}$. The pretreatment was followed by the synthesis gas stream with $\mathrm{H}_{2} / \mathrm{CO}=1$ and space velocity of $3.07 \mathrm{nl} \cdot \mathrm{h}^{-1} \cdot \mathrm{g}_{\mathrm{Fe}}{ }^{-1}$ for $24 \mathrm{~h}$ in $0.1 \mathrm{Mpa}$ and $543 \mathrm{~K}$. After catalyst pretreatment, synthesis gas was feed to the reactor at $563 \mathrm{~K}, 17 \mathrm{bar},\left(\mathrm{H}_{2} / \mathrm{CO}\right)_{\mathrm{feed}}=1$ and a space velocity of $4.9 \mathrm{nl} \cdot \mathrm{h}^{-1} \cdot \mathrm{g}_{\mathrm{Fe}}{ }^{-1}$.

The products were analyzed by means of three gas chromatographs, a Shimadzu 4C gas chromatograph equipped with two subsequent connected packed columns: Porapak Q and Molecular Sieve 5A, and a thermal conductivity detector (TCD) with Ar as carrier gas for hydrogen analyzing. A Varian CP 3800 with a chromosorb column and a thermal conductivity detector (TCD) were used for $\mathrm{CO}, \mathrm{CO}_{2}, \mathrm{CH}_{4}$, and other noncondensable gases. A Varian CP 3800 with a Petrocol DH100 fused silica capillary column and a flame ionization detector (FID) were used for organic liquid products so that a complete product distribution could be provided.

\section{Results and Discussion}

3.1. Catalyst Characterization. Nanostructure iron catalysts were characterized by X-ray diffraction (XRD) measurement after calcinations (Figure 1). As shown in Figure 1, XRD patterns of samples very close to the ones with cubic hematite structured $\mathrm{Fe}_{2} \mathrm{O}_{3}$ crystal in JCPDS database. The characteristic peaks corresponding to (012), (104), (110), (113), (024), (116), (018), (214), and (300) planes are located at $2 \theta=24.3$, $33.3,35.8,40.8,49.6,54.1,57.6,64.1$, and $65.6^{\circ}$, respectively. Diffraction data indicates that the presence of lanthanum and copper and also subsequent treatment by dried air do not affect the hematite crystalline phases in different catalyst preparation methods. This shows that the formed
TABLE 1: Average particle size determined by TEM, BET, and XRD techniques.

\begin{tabular}{lccc}
\hline HLB & $d_{\text {BET }}(\mathrm{nm})$ & $d_{\text {XRD }}(\mathrm{nm})$ & $d_{\text {TEM }}(\mathrm{nm})$ \\
\hline 13.9 & 16.8 & 15.4 & 14 \\
23.7 & 20.3 & 18.8 & 17 \\
31.2 & 22.1 & 20.6 & 21 \\
40 & 26.3 & 24.8 & 24 \\
\hline
\end{tabular}

TABLE 2: Textural properties of prepared catalysts.

\begin{tabular}{lccc}
\hline HLB & $\begin{array}{r}\text { BET surface area } \\
\left(\mathrm{m}^{2} / \mathrm{g}\right)\end{array}$ & $\begin{array}{r}\text { Average pore size } \\
(\mathrm{nm})^{\mathrm{a}}\end{array}$ & $\begin{array}{c}\text { Pore volume } \\
\left(\mathrm{cm}^{3} / \mathrm{g}\right)^{\mathrm{a}}\end{array}$ \\
\hline 13.9 & 68.2 & 16.2 & 0.14 \\
23.7 & 56.4 & 19.6 & 0.16 \\
31.2 & 51.8 & 22.3 & 0.19 \\
40 & 43.5 & 25.9 & 0.21 \\
\hline
\end{tabular}

${ }^{\mathrm{a}}$ These values were calculated by $\mathrm{BJH}$ method from desorption isotherm.

hematite structure remains stable during subsequent aqueous impregnation and thermal treatment. It was also shown in Figure 1 that the microemulsion system only modules the physical properties of reaction medium without changing the reaction paths and arrangements of crystal structure. The characteristic peak at $2 \theta=33.3^{\circ}$ which corresponds to the hematite 104 plane was used to calculate the average metal particle size by the Scherrer equation. The calculated values of $d_{\mathrm{XRD}}$ of the samples are listed in Table 1 .

Textural properties and pore size distributions of the fresh iron-based catalysts are shown in Table 2 and Figures 2 and 3, respectively. $\mathrm{N}_{2}$ adsorption-desorption isotherms of catalysts are presented in Figure 3. As shown in this Figure, the prepared catalysts show type IV of Brunauer's classification isotherms with $\mathrm{H}_{1}$-type hysteresis loop at the relative pressure of $P / P_{0}=0.8-0.95$. This hysteresis loop is characterized as hexagonal mesoporous materials with cylindrical channels [19].

The pore size distributions of the catalysts which were calculated by Barrett-Joyner-Halenda (BJH) method for adsorption step are presented in Figure 3 and Table 2. Since all pore size values are fairly close to the dimension of particles, it deduces that the measured pore size is mainly caused by the inter particle voids.

The TEM photographs for the prepared samples are demonstrated in Figure 4 and Table 1 and also the particle size distribution determined by TEM images are shown in Figure 5 . The average particle size $\left(d_{\mathrm{TEM}}\right)$ and particle size distribution were obtained from TEM images by considering more than 100 particles. As shown in Figures 4 and 5, the average range of particle size and particle size distribution increases as HLB value increases.

The particle size of samples which were determined by XRD, BET, and TEM techniques are summarized in Table 1. Particle sizes which were estimated by different techniques provide different physical explanation. The particle size obtained from XRD pattern $\left(d_{\mathrm{XRD}}\right)$ indicates the average 


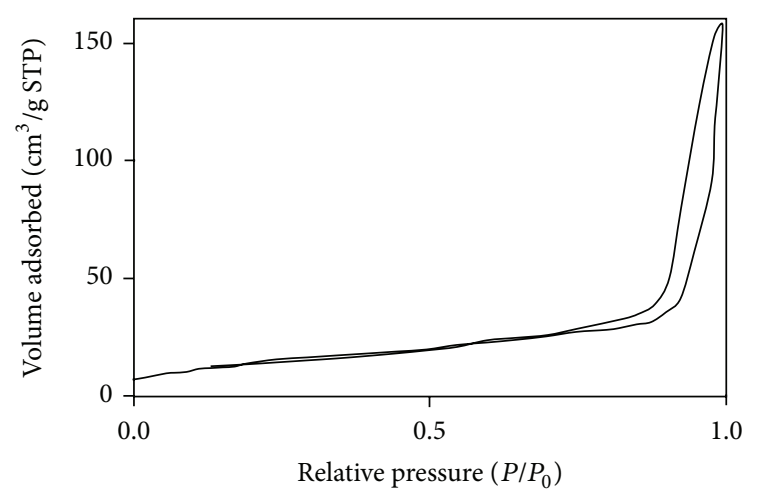

(a)

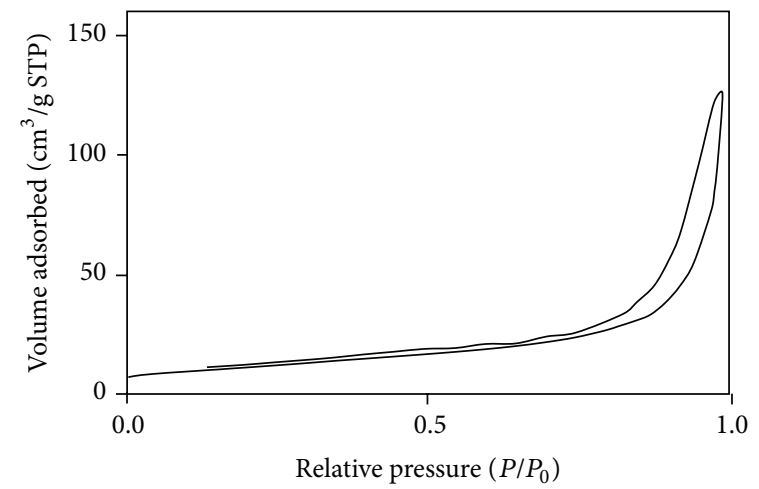

(c)

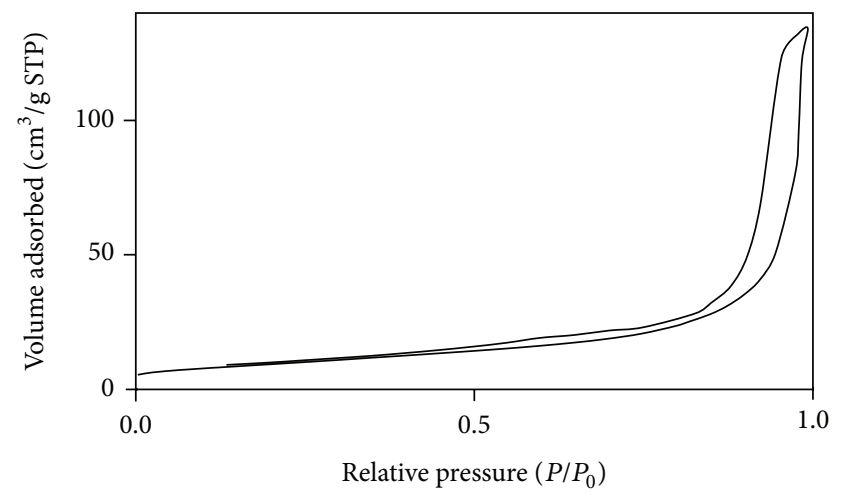

(b)

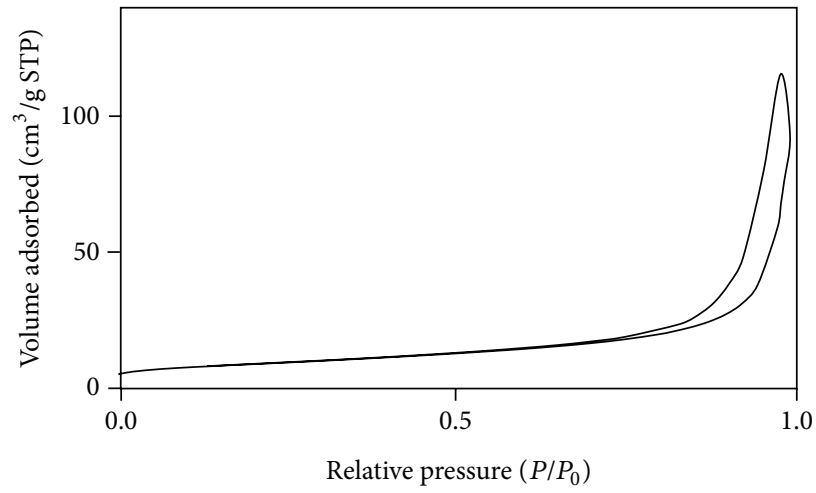

(d)

Figure 2: $\mathrm{N}_{2}$ adsorption-desorption hysteresis at $77 \mathrm{~K}$ of prepared catalysts after calcinations ((a) HLB = 13.9, (b) HLB = 23.7, (c) HLB = 31.2, and (d) HLB $=40)$.

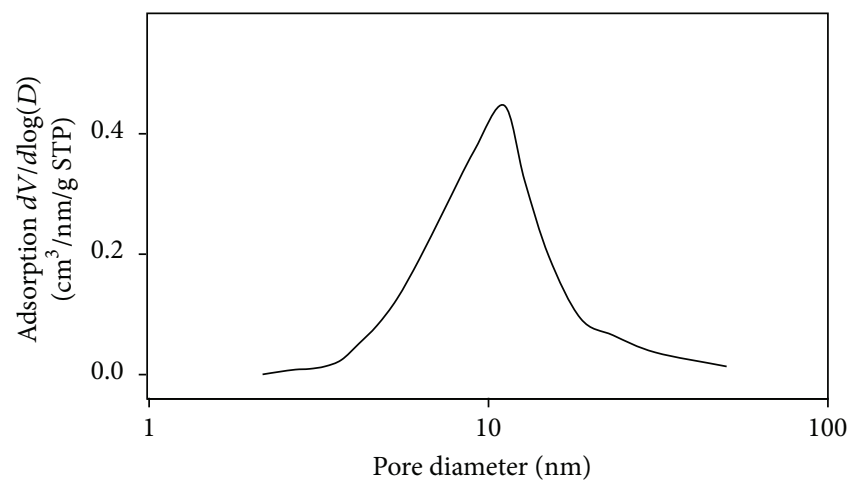

(a)

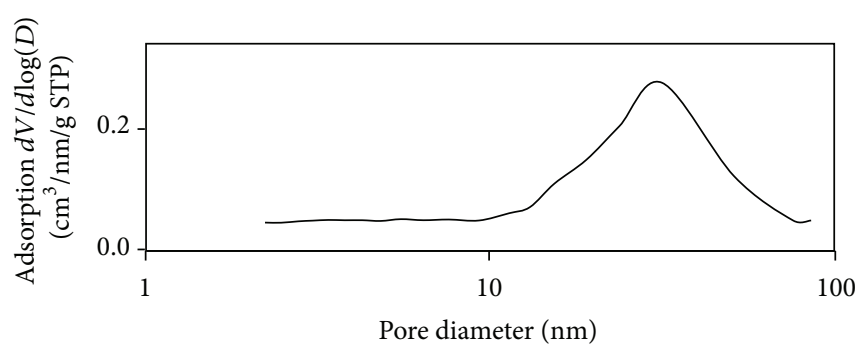

(c)

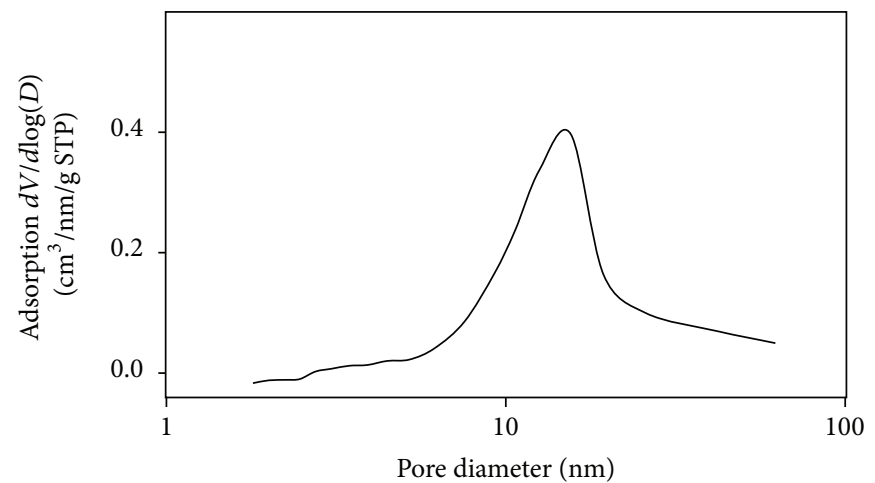

(b)

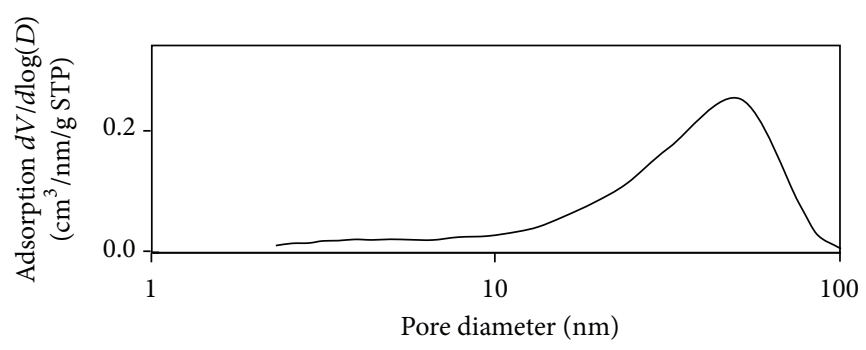

(d)

FIGURE 3: Adsorption BJH pore size distribution of prepared catalysts after calcinations ((a) HLB = 13.9, (b) HLB = 23.7, (c) HLB = 31.2, and (d) HLB = 40). 


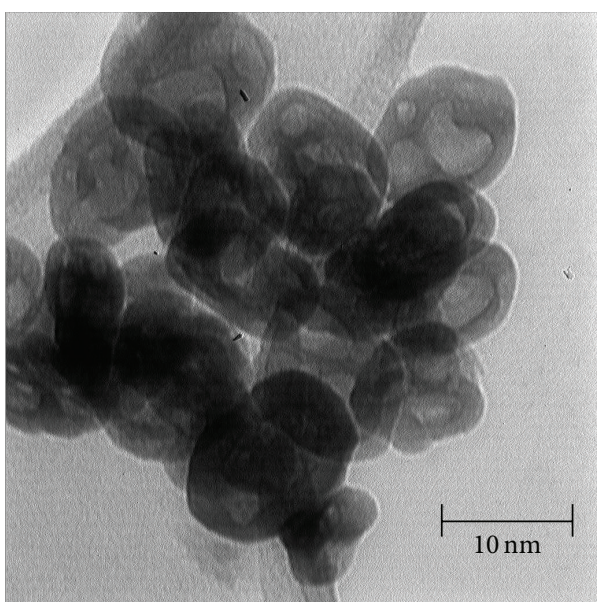

(a)

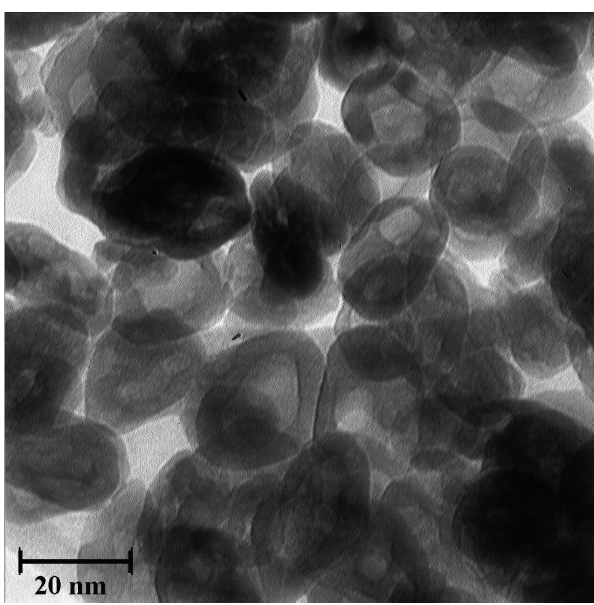

(c)

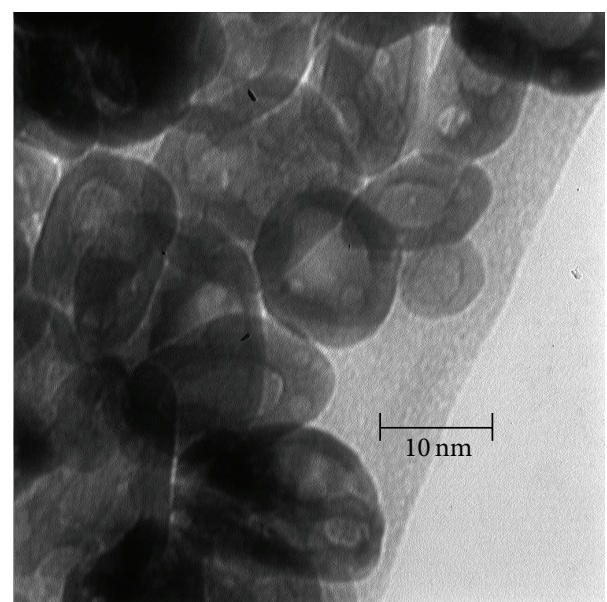

(b)

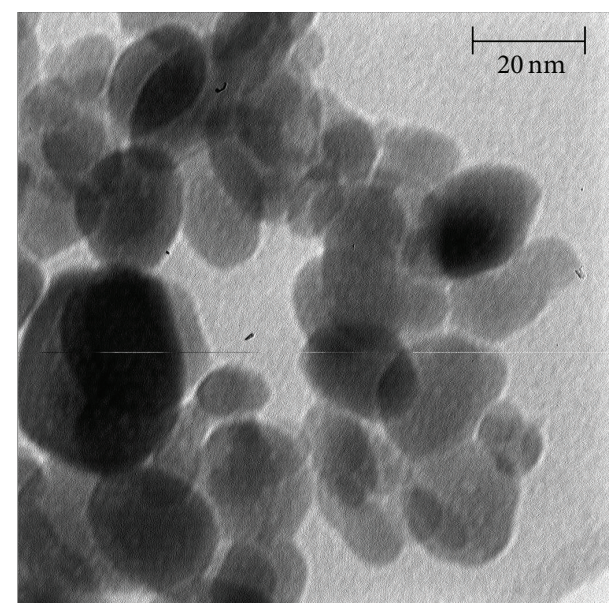

(d)

Figure 4: TEM image of prepared catalysts after calcinations ((a) HLB = 13.9, (b) HLB = 23.7, (c) HLB = 31.2, and (d) HLB = 40).

crystallite size of particles. The $d_{\mathrm{BET}}$ value is calculated from surface area which is measured by nitrogen adsorptiondesorption assuming that the particles are spherical and nonporous. The $d_{\mathrm{XRD}}$ and $d_{\mathrm{BET}}$ possess the cumulative and comprehensive information on particle size, although they are derived indirectly. However, the $d_{\mathrm{TEM}}$ value is a direct evidence of average particle size of $\mathrm{Fe}_{2} \mathrm{O}_{3}$ suspension and thus in this work, it has been used for further calculations.

As shown in Table 1, the particle size is increased and the particle size distribution becomes wider with the increase of HLB value. In fact, nanoparticles are formed in the internal structure of the microemulsion, which is determined by the HLB value of surfactant. The results show that the size of different droplets determines the hematite particle size, depending on the HLB value of surfactant.

The effects of the iron particle size on the reduction behavior of the catalysts were measured by $\mathrm{H}_{2}$-TPR. The profiles of $\mathrm{H}_{2}$-TPR are presented in Figure 6. As shown in Figure 6, all catalysts present two main reduction peaks at about 700 and $900 \mathrm{~K}$ in the $\mathrm{H}_{2}$-TPR profiles. It has been postulated that the first stage corresponds to the reductions of $\alpha-\mathrm{Fe}_{2} \mathrm{O}_{3}$ to magnetite $\left(\mathrm{Fe}_{3} \mathrm{O}_{4}\right)$ and $\mathrm{CuO}$ to $\mathrm{Cu}$, whereas the second stage corresponds to the subsequent reduction of $\mathrm{Fe}_{3} \mathrm{O}_{4}$ to metallic iron $(\alpha-\mathrm{Fe})[15,16]$. It is also found that the first stage can be further separated into two peaks, the first peak corresponds to the reduction of the solid solution of $\mathrm{CuO}$ and part of $\alpha-\mathrm{Fe}_{2} \mathrm{O}_{3}$ to $\mathrm{Cu}$ and $\mathrm{Fe}_{3} \mathrm{O}_{4}$, and the second small peak is ascribed to the reduction of the residual $\alpha$ $\mathrm{Fe}_{2} \mathrm{O}_{3}$ to $\mathrm{Fe}_{3} \mathrm{O}_{4}$. The presence of $\mathrm{Cu}$ in iron catalyst reduces $\alpha-\mathrm{Fe}_{2} \mathrm{O}_{3}$ to $\mathrm{Fe}_{3} \mathrm{O}_{4}$ at lower temperature rather than $\mathrm{Cu}$ free samples. As $\mathrm{CuO}$ reduces, $\mathrm{Cu}$ crystallites nucleate and provide $\mathrm{H}_{2}$ dissociation sites, which in turn lead to reactive hydrogen species capable of reducing iron oxides at relatively low temperatures $[8,9]$.

The TPR profiles in Figure 6 clearly show that the first reduction peaks of the catalysts shift to the lower temperature with the decrease of the iron particle size. The probable reason is higher interaction between iron and copper oxides in homogeneous phase of the catalyst prepared via microemulsion system. This suggests that the microemulsion technique promotes the dispersion of $\mathrm{Cu}$ promoter, which subsequently enhances the effect of $\mathrm{Cu}$ promoter, improves the reduction 


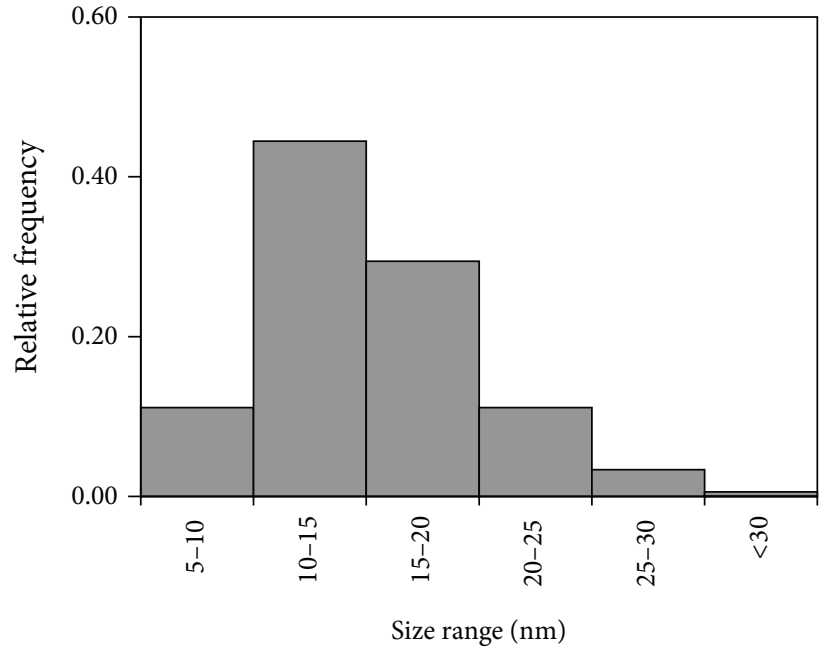

(a)

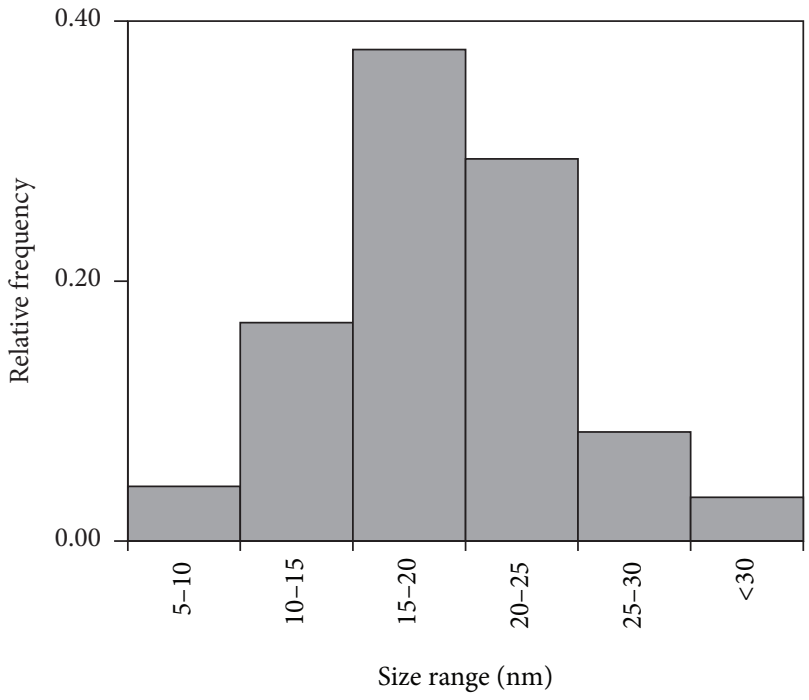

(c)

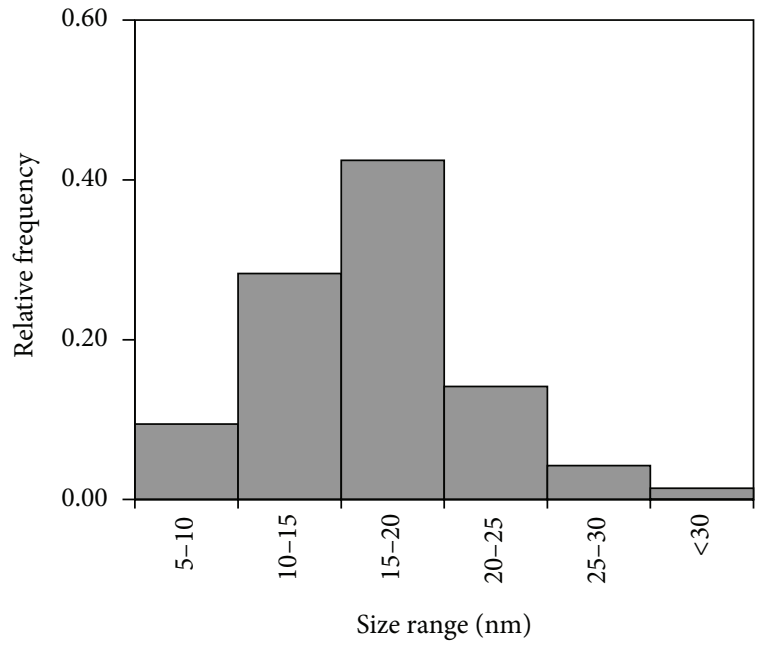

(b)

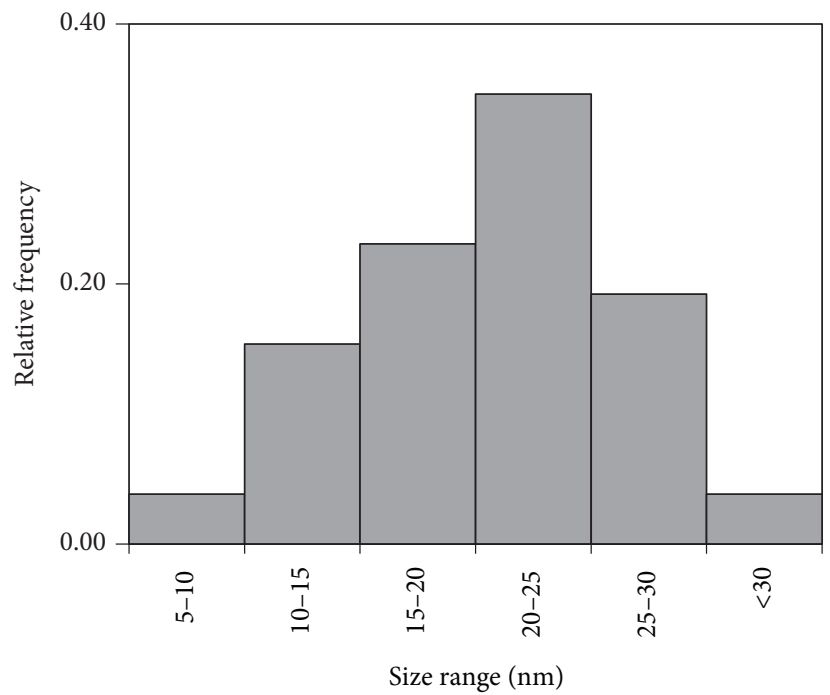

(d)

FIGURE 5: Relative particle size distribution of prepared catalysts after calcinations ((a) HLB = 13.9, (b) HLB = 23.7, (c) HLB = 31.2, (d) HLB $=40)$.

of the $\alpha-\mathrm{Fe}_{2} \mathrm{O}_{3}$, and decreases the reduction temperature for first peak in $\mathrm{H}_{2}$-TPR profile.

The amount of the consumed $\mathrm{H}_{2}$ during different reduction stages which is obtained from integrating the area of the corresponding reduction peak is summarized in Table 3. The overall $\mathrm{H}_{2}$ consumption $\left[\mathrm{mol} \mathrm{H}_{2} / \mathrm{mol} \mathrm{M}(\mathrm{Fe}+\mathrm{Cu})\right]$ of the first reduction peaks can be assigned to the reduction of $\mathrm{CuO}$ and also the reduction of $\alpha-\mathrm{Fe}_{2} \mathrm{O}_{3}$ to $\mathrm{Cu}$ and $\mathrm{Fe}_{3} \mathrm{O}_{4}$, respectively. In the first stage of reduction, $\mathrm{CuO}$ and $\mathrm{Fe}_{2} \mathrm{O}_{3}$ reacted with hydrogen based on the following reactions:

$$
\begin{aligned}
& 3 \mathrm{Fe}_{2} \mathrm{O}_{3}+\mathrm{H}_{2} \longrightarrow 2 \mathrm{Fe}_{3} \mathrm{O}_{4}+\mathrm{H}_{2} \mathrm{O} \\
& \left(\frac{\mathrm{mol} \mathrm{H}}{\mathrm{mol} \mathrm{Fe}}=0.166 \text { for complete reduction }\right),
\end{aligned}
$$

$$
\begin{aligned}
& \mathrm{CuO}+\mathrm{H}_{2} \longrightarrow \mathrm{Cu}+\mathrm{H}_{2} \mathrm{O} \\
& \left(\frac{\mathrm{mol} \mathrm{H}}{\mathrm{mol} \mathrm{Cu}}=1 \text { for complete reduction }\right) .
\end{aligned}
$$

The peaks at $851 \mathrm{~K}\left(\mathrm{~mol} \mathrm{H}_{2} / \mathrm{mol} \mathrm{Fe}\right)$ correspond to the reduction of $\mathrm{Fe}_{3} \mathrm{O}_{4}$ to $\mathrm{Fe}$ as below:

$$
\begin{aligned}
& \mathrm{Fe}_{3} \mathrm{O}_{4}+4 \mathrm{H}_{2} \longrightarrow 3 \mathrm{Fe}+4 \mathrm{H}_{2} \mathrm{O} \\
& \left(\frac{\mathrm{mol} \mathrm{H}}{\mathrm{mol} \mathrm{Fe}}=1.33 \text { for complete reduction }\right) .
\end{aligned}
$$

The peaks at higher temperature (above $900 \mathrm{~K}$ ) may be due to the reduction of $\mathrm{FeO}$ to $\mathrm{Fe}$ and the $\mathrm{H}_{2}$ consumptions which are consistent with theoretical values.

As shown in Figure 6 and Table 3, smaller crystal size of the catalyst has also influence on the reduction of $\mathrm{Fe}_{3} \mathrm{O}_{4}$ to 


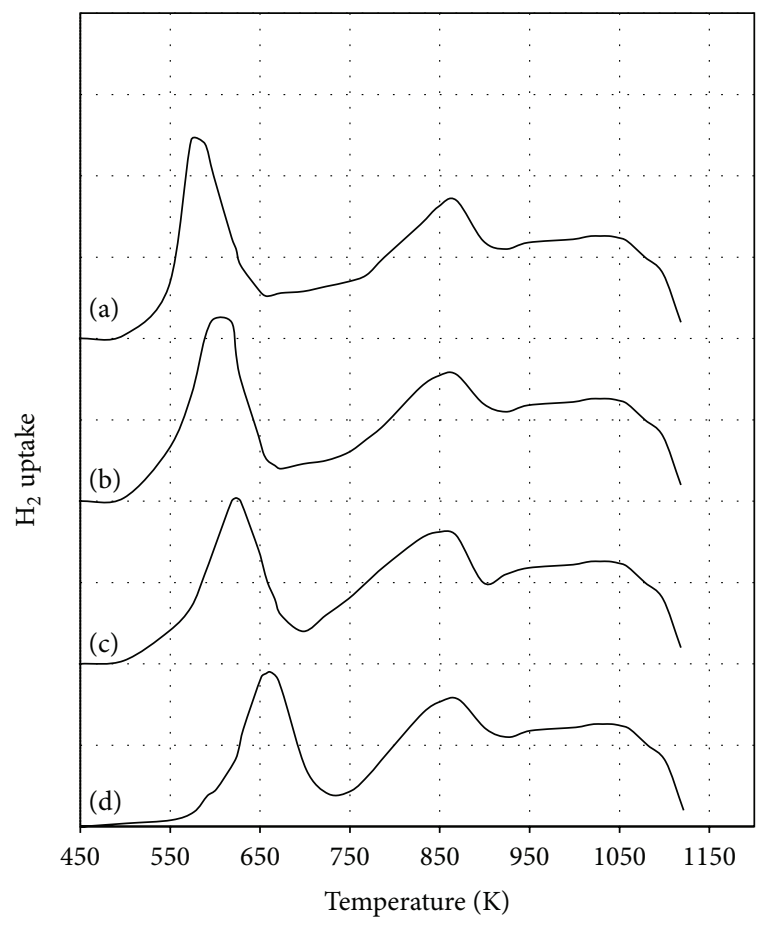

FIGURE 6: TPR profiles of prepared catalysts after calcinations ((a) HLB $=13.9$, (b) HLB = 23.7, (c) HLB = 31.2, and (d) HLB = 40).

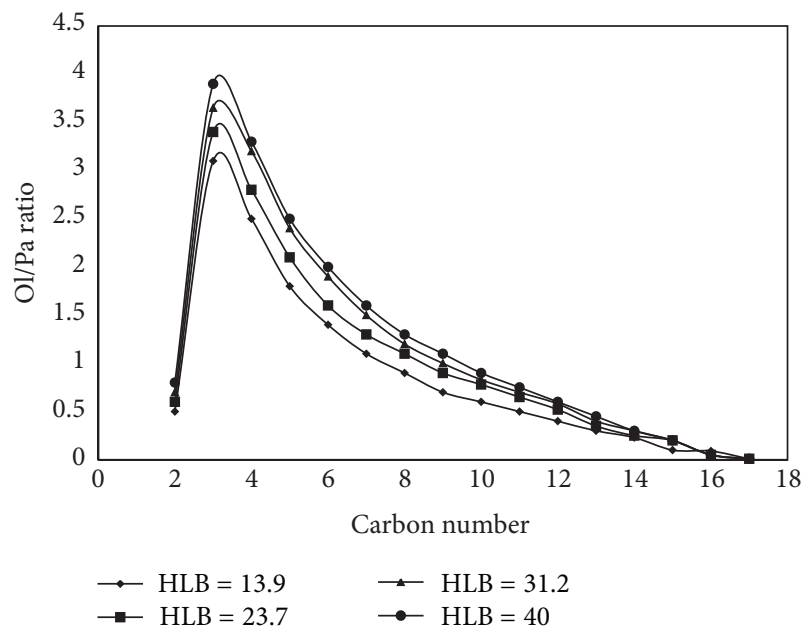

FIgURE 7: Olefin-to-paraffin ratio in products after $35 \mathrm{~h}$ time-onstream, reaction conditions: $583 \mathrm{~K}, 17 \mathrm{bar},\left(\mathrm{H}_{2} / \mathrm{CO}\right)_{\text {feed }}=1$, and space velocity of $4.9 \mathrm{nl} \cdot \mathrm{h}^{-1} \cdot \mathrm{g}_{\mathrm{Fe}}{ }^{-1}((\mathrm{a}) \mathrm{HLB}=13.9$, (b) HLB $=23.7$, (c) HLB $=31.2$, and $(\mathrm{d})$ HLB $=40)$.

$\alpha$-Fe as well as first reduction step. The results show that the amount of the catalyst reduction increased with decreasing the catalyst crystal size.

3.2. Catalytic Activity. The effect of the catalyst particle size on catalyst activity, product selectivity, and hydrocarbon distribution at the same time-on stream is listed in Table 4. It was found that the $\mathrm{CO}$ and $\mathrm{H}_{2}$ conversion was increased while the HLB value of surfactant decreased. It is also shown in this table that the methane and $\mathrm{CO}_{2}$ selectivity increased while the catalyst particle size decreased. Moreover, higher hydrocarbon selectivity and chain growth probability $(\alpha)$ decreased when the crystal size decreased.

Olefin-to-paraffin ratio in products and olefin and paraffin production rates after $35 \mathrm{~h}$ time-on-stream are shown in Figures 7 and 8. As listed in Table 4 and shown in Figures 7 and 8 , olefin selectivity is decreased by reduction of the HLB value of the surfactant (catalyst particle size decreased). Also as shown in Figures 7 and 8, olefin selectivity decreases with increasing the olefins carbon number.

The catalytic properties of nanoparticles depend on the size of catalysts active site. Thus, different sizes of nanoparticles have different catalytic activity and selectivity. The dynamic surface restructuring of nanoparticles should also depend on their size; that is, smaller nanoparticles have higher surface energies. For the heterogeneous catalytic reactions, adsorption equilibrium constant of feed increased with decreasing the particle size $[13,14]$. By increasing the adsorption equilibrium constant of hydrogen and carbon monoxide on surface of iron catalysts in small particles, the catalyst reduction and FTS reaction increased. Also, higher activity of the iron catalyst with lower particle size (Table 4) may be related to the reduction ability of the catalysts that increased with the particle size (Figure 6 and Table 3).

It is postulated that 1-alkenes are primary products of the FTS reaction over iron-based catalyst and may be transformed to paraffin by hydrogenation as a secondary reaction $[20,21]$. Secondary reactions occur when primary products desorbed from a site and then interact with another catalytic site before leaving the catalyst particles. Secondary reactions can influence the type and molecular weight of the hydrocarbon products. Hydrogenation of 1-alkenes to paraffin is the most famous secondary reaction in FT synthesis. Thus, the extent of secondary reactions can also be observed from the dependency of the $O_{n} / P_{n}$ ratio or olefin content on chain length. The ratio of olefins to paraffins depends on catalyst type, structure, and the reaction conditions. Slow removal of reactive products (e.g., $\alpha$-olefins) due to the reduction of diffusion coefficients with increasing chain length can influence the FTS reaction rate and selectivity. The results presented in Table 4 show that the olefin/paraffin ratios are decreased with increasing catalyst particle size.

Van der Laan and Beenackers emphasized the solubility impact (vapor-liquid equilibrium) over diffusion as the main contributor on secondary reactions [21]. As shown in Table 4, the secondary reactions are increased $(O / P$ decreased) in the lower iron particle size because of some difficulties of olefin diffusion in nanoparticles with narrow pores. On the other hand, the steric hindrance can limit the competitive adsorption of bigger molecules on smaller crystal sizes. Thus, increasing the adsorption equilibrium constant by decreasing iron particle size is more for hydrogen than that of carbon monoxide [8-12]. Higher hydrogen concentrations on smaller particles enhance the hydrogenation of olefin. The results presented in Figures 7 and 8 and Table 4 show that the olefin/paraffin ratios are decreased with increasing the catalyst particle size of the samples.

Anderson-Schultz-Floury (ASF) distribution of FTS products on catalysts is presented in Figure 9. Product 


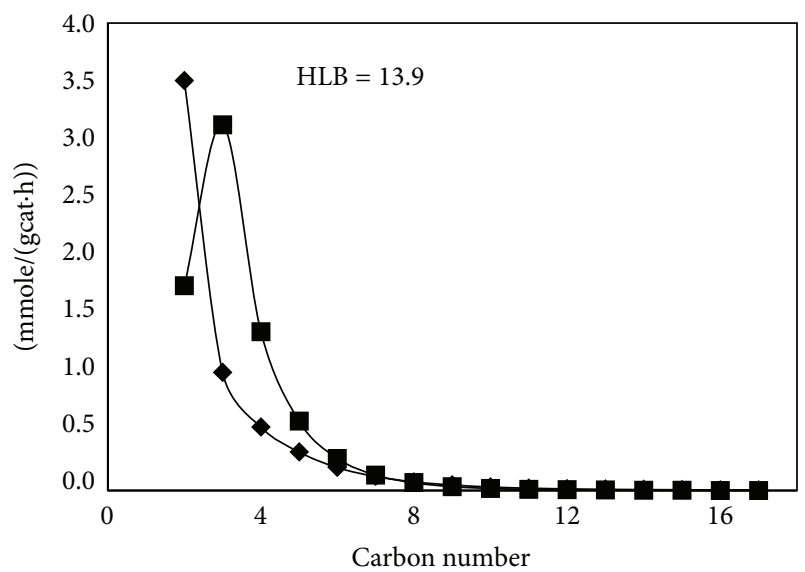

(a)

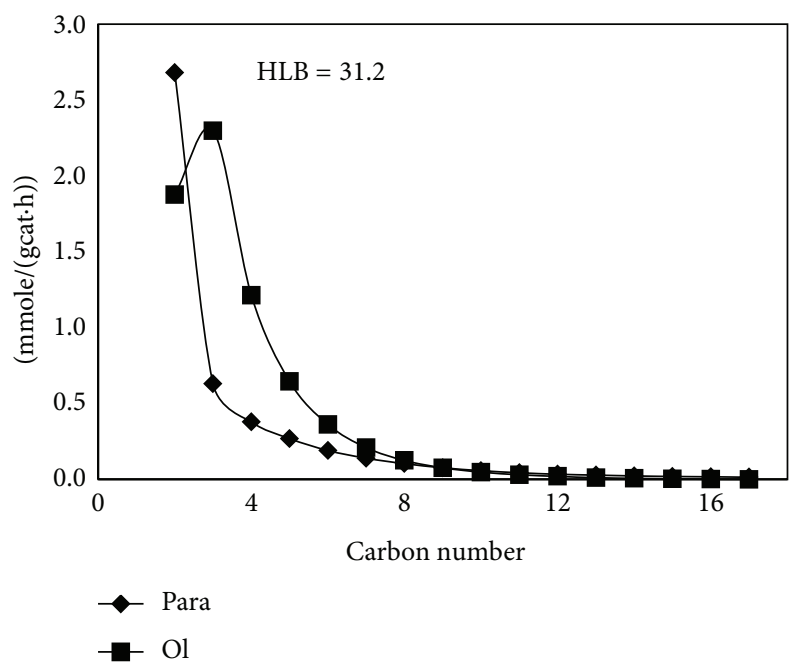

(c)

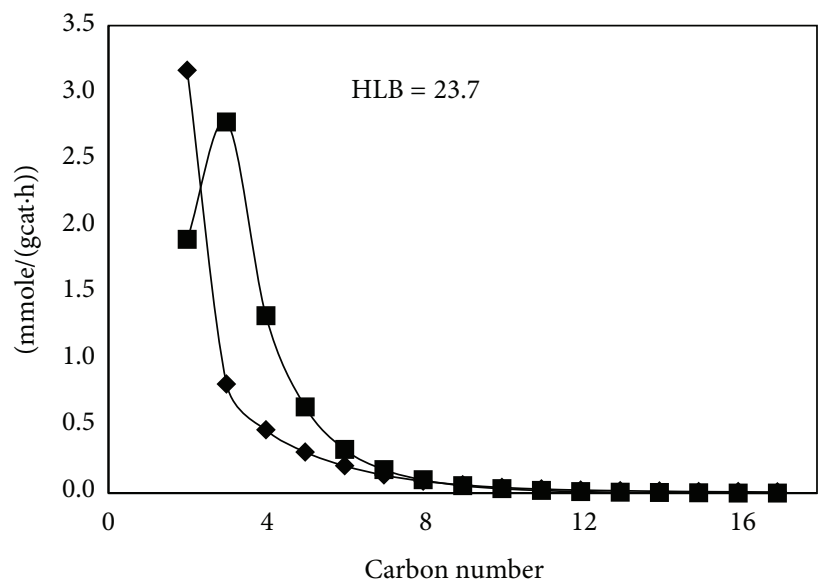

(b)

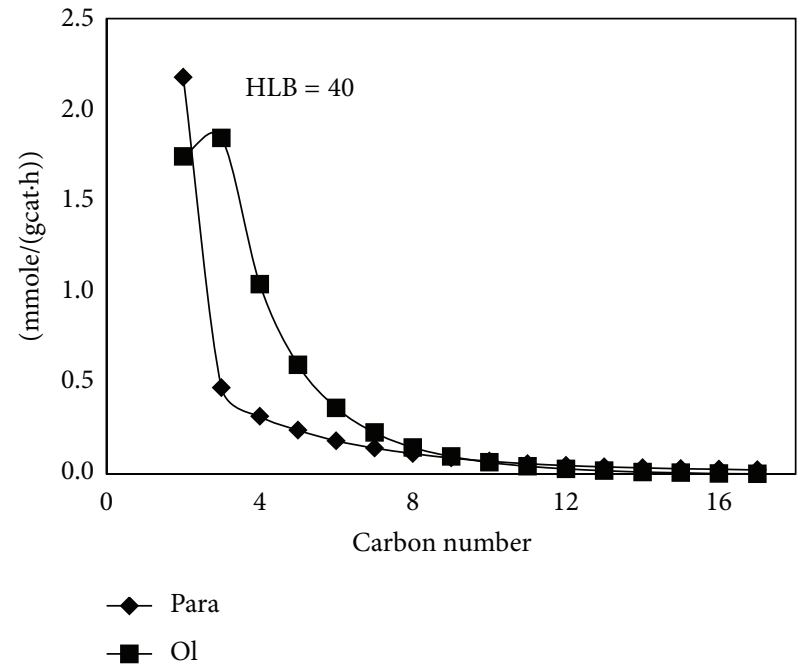

(d)

FIGURE 8: Olefin and paraffin production rates after $35 \mathrm{~h}$ time-on-stream, and reaction conditions: $583 \mathrm{~K}, 17 \mathrm{bar},\left(\mathrm{H}_{2} / \mathrm{CO}\right)_{\mathrm{feed}}=1$, space velocity of $4.9 \mathrm{nl} \cdot \mathrm{h}^{-1} \cdot \mathrm{g}_{\mathrm{Fe}}{ }^{-1}$ ((a) HLB $=13.9$, (b) HLB $=23.7$, (c) HLB = 31.2, and (d) HLB = 40).

TABLE 3: Quantitative results of $\mathrm{H}_{2}$ consumption for catalysts in $\mathrm{H}_{2}-\mathrm{TPR}^{\mathrm{a}}$.

\begin{tabular}{|c|c|c|c|c|}
\hline \multirow{2}{*}{ HLB } & \multirow{2}{*}{ Peak (K) } & \multicolumn{2}{|c|}{$\mathrm{H}_{2}$ consumption } & \multirow{2}{*}{$\%$ Reduction } \\
\hline & & $\mathrm{mol} \mathrm{H}_{2} / \mathrm{mol} \mathrm{M}^{\mathrm{b}}$ & $\mathrm{mol} \mathrm{H}_{2} / \mathrm{mol} \mathrm{Fe}$ & \\
\hline \multirow{2}{*}{13.9} & 533 & 0.171 & & \multirow{2}{*}{93} \\
\hline & 850 & & 1.24 & \\
\hline \multirow{2}{*}{23.7} & 558 & 0.163 & & \multirow{2}{*}{87} \\
\hline & 851 & & 1.16 & \\
\hline \multirow{2}{*}{31.2} & 608 & 0.154 & & \multirow{2}{*}{84} \\
\hline & 842 & & 1.12 & \\
\hline \multirow{2}{*}{40} & 640 & 0.142 & & \multirow{2}{*}{79} \\
\hline & 852 & & 1.06 & \\
\hline
\end{tabular}

${ }^{\mathrm{a}} \mathrm{The} \mathrm{H}_{2}$ consumption was measured from the area under the corresponding peak.

${ }^{\mathrm{b}} \mathrm{M}=\mathrm{Fe}+\mathrm{Cu}$. 
TABLE 4: Catalysts activity and products selectivity after $35 \mathrm{~h}$ time-on-stream.

\begin{tabular}{|c|c|c|c|c|c|c|c|c|c|}
\hline \multirow{2}{*}{ HLB } & \multirow{2}{*}{$\mathrm{X}_{\mathrm{CO}}^{\mathrm{a}}$} & \multirow{2}{*}{$\mathrm{HC}^{\mathrm{b}}$} & \multirow{2}{*}{$\mathrm{O} / \mathrm{P}^{\mathrm{c}}$} & \multirow{2}{*}{$\alpha^{\mathrm{d}}$} & \multirow{2}{*}{$\mathrm{CO}_{2}(\%)^{\mathrm{e}}$} & \multicolumn{4}{|c|}{ Products selectivity } \\
\hline & & & & & & $\mathrm{CH}_{4}$ & $\mathrm{C}_{2}-\mathrm{C}_{4}$ & $\mathrm{C}_{5}-\mathrm{C}_{12}$ & $\mathrm{C}_{12+}$ \\
\hline 40 & 67.2 & 21.3 & 1.1 & 0.83 & 31.3 & 13.7 & 41.7 & 35.0 & 9.6 \\
\hline 31.2 & 71.5 & 22.2 & 1.0 & 0.8 & 32.2 & 14.6 & 47.6 & 31.5 & 6.3 \\
\hline 23.7 & 75.2 & 22.8 & 1.0 & 0.78 & 33.1 & 15.6 & 53.2 & 27.4 & 3.8 \\
\hline 13.9 & 77.5 & 23.5 & 0.9 & 0.75 & 34.5 & 17.6 & 57.5 & 22.8 & 2.1 \\
\hline
\end{tabular}

Reaction conditions: $563 \mathrm{~K}, 1.7 \mathrm{Mpa}$, and $\mathrm{H}_{2} / \mathrm{CO}=1$ and space velocity $=4.9 \mathrm{nl} \cdot \mathrm{h}^{-1} \cdot \mathrm{g}_{\mathrm{Fe}}{ }^{-1}$.

${ }^{a}$ Carbon monoxide conversion ( $\left.\mathrm{mol} \%\right)$.

${ }^{\mathrm{b}} \mathrm{Hydrocarbon}$ production, $\mathrm{gCH} / \mathrm{gFe} / \mathrm{s}\left(\times 10^{5}\right)$, and $\mathrm{CH}_{4}$ free.

c Olefin to paraffin ratio.

${ }^{\mathrm{d}}$ Chain growth probability.

${ }^{e} \mathrm{CO}_{2}$ selectivity: selectivity to oxygenates was negligible $(<2.0 \%)$ in all cases.

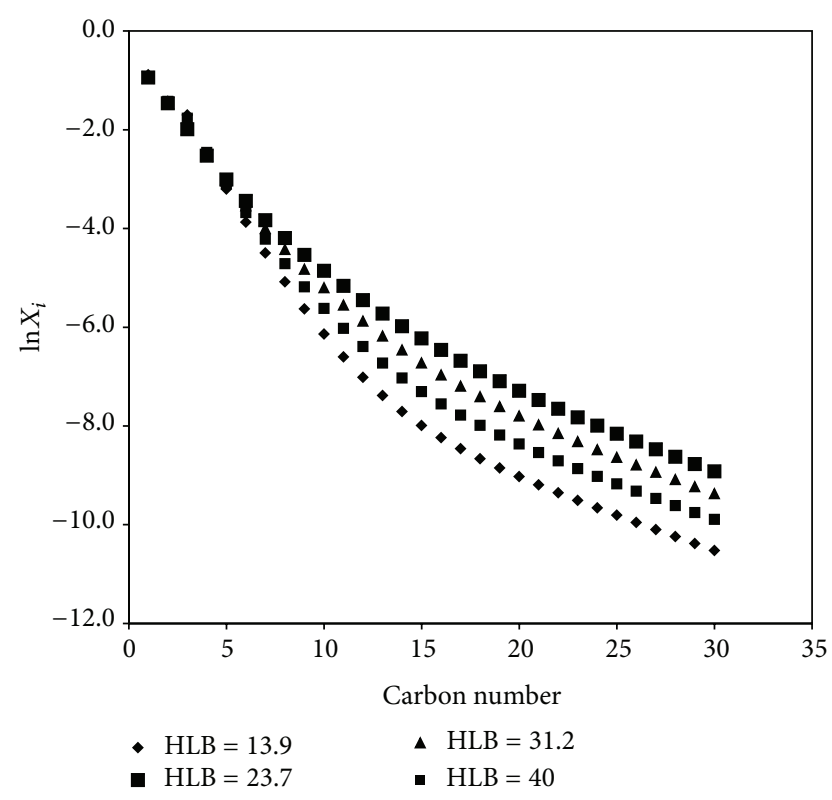

FIGURE 9: Overall products distributions on catalysts after $35 \mathrm{~h}$ timeon-stream, reaction conditions: $583 \mathrm{~K}, 17 \mathrm{bar},\left(\mathrm{H}_{2} / \mathrm{CO}\right)_{\text {feed }}=1$, space velocity of $4.9 \mathrm{nl} \cdot \mathrm{h}^{-1} \cdot \mathrm{g}_{\mathrm{Fe}}{ }^{-1}$ ((a) HLB $=13.9$, (b) HLB $=23.7$, (c) $\mathrm{HLB}=31.2$, and $(\mathrm{d}) \mathrm{HLB}=40)$.

distribution shows a slight shift to the lower molecular weight hydrocarbons by decreasing the HLB value of the surfactant. The trend lines are plotted to determine the chain growth probability, $\alpha$. As listed in Table 4 , the chain growth probabilities were $0.83,0.8,0.78$, and 0.75 for $40,31.2,23.7$, and $13.9 \mathrm{HLB}$ value of surfactant, respectively. This confirms the higher molecular weight hydrocarbons production using higher HLB value of surfactant in preparation of catalyst. As mentioned in the previous section, higher HLB value of surfactant produced higher particle size of catalysts.

Figure 9 and Table 4 also show the effects of the catalyst particle size on the selectivity of Fischer-Tropsch synthesis products. Comparison of the product distributions of the catalysts clearly shows that the product distribution shift to the lower molecular weight hydrocarbons by decreasing the HLB value of the surfactant (or decreasing the catalyst particle size).
The most accepted mechanism for FTS reaction is $\mathrm{C}_{1}$ insertion which leads to the carbide theory [21]. These $C_{1}$ species have various hydrogenation degrees as follows: $\mathrm{CO}$, $\mathrm{HCO}, \mathrm{HCOH}, \mathrm{CH}$, and $\mathrm{CH}_{2}$. Literature results $[19,20]$ have discussed that light hydrocarbons are built up by monomers that exhibited higher degree of hydrogenation, that is, $\mathrm{CH}_{2}$. Obviously, heavy hydrocarbons are built up due to monomers except $\mathrm{CH}_{2}$ species with lower degree of hydrogenation. With increasing the hydrogen concentration on the surface of the catalyst, the concentration of $\mathrm{C}_{1}$ monomers with higher degree of hydrogenation are increased. Increasing the concentration of hydrogen on the surface of the catalysts as a result of reduction of the catalyst particle size increases the concentration of $\mathrm{C}_{1}$ monomers and ultimately leads to the higher selectivity to the lower hydrocarbons being enhanced.

\section{Conclusion}

Nanosized iron oxide particles have been successfully synthesized by reverse microemulsion with different HLB values. The iron oxide particle size and particle size distribution are increased by decreasing of HLB values. It was found that the $\mathrm{CO}$ and $\mathrm{H}_{2}$ conversion is increased as the HLB value of the surfactant is reduced. Also the methane and $\mathrm{CO}_{2}$ selectivity is increased at the same time as the catalyst particle size is decreased. In addition, higher hydrocarbon selectivity and chain growth probability $(\alpha)$ show a descending trend in carbon number when the crystal size decreases.

\section{Acknowledgment}

Financial support of the Ferdowsi University of Mashhad, Iran $(\mathrm{P} / 15369 / 1-89 / 8 / 5)$ is gratefully acknowledged.

\section{References}

[1] A. T. Bell, "The impact of nanoscience on heterogeneous catalysis," Science, vol. 299, no. 5613, pp. 1688-1691, 2003.

[2] J. Y. Ying, "Design and synthesis of nanostructured catalysts," Chemical Engineering Science, vol. 61, no. 5, pp. 1540-1548, 2006.

[3] X. Zhou, W. Xu, G. Liu, D. Panda, and P. Chen, "Size dependent catalytic activity and dynamics of gold nanoparticles at 
the single-molecule level," Journal of the American Chemical Society, vol. 132, no. 1, pp. 138-146, 2010.

[4] P. Kumar and K. L. Mittal, Handbook of Microemulsions: Science and Technology, Marcel Dekker, New York, NY, USA, 1999.

[5] S. Eriksson, U. Nylén, S. Rojas, and M. Boutonnet, "Preparation of catalysts from microemulsions and their applications in heterogeneous catalysis," Applied Catalysis A, vol. 265, no. 2, pp. 207-219, 2004.

[6] I. Capek, "Preparation of metal nanoparticles in water-inoil (w/o) microemulsions," Advances in Colloid and Interface Science, vol. 110, no. 1-2, pp. 49-74, 2004.

[7] G. Guo, Y. Sun, Z. Wang, and H. Guo, "Preparation of hydroxyapatite nanoparticles by reverse microemulsion," Ceramics International, vol. 31, no. 6, pp. 869-872, 2005.

[8] T. Herranz, S. Rojas, F. J. Pérez-Alonso, M. Ojeda, P. Terreros, and J. L. G. Fierro, "Hydrogenation of carbon oxides over promoted $\mathrm{Fe}-\mathrm{Mn}$ catalysts prepared by the microemulsion methodology," Applied Catalysis A, vol. 311, pp. 66-75, 2006.

[9] A. Sarkar, D. Seth, A. K. Dozier, J. K. Neathery, H. H. Hamdeh, and B. H. Davis, "Fischer-Tropsch synthesis: morphology, phase transformation and particle size growth of nano-scale particles," Catalysis Letters, vol. 117, no. 1-2, pp. 1-17, 2007.

[10] A. Nakhaei Pour, S. Taghipoor, M. Shekarriz, S. M. K. Shahri, and Y. Zamani, "Fischer-tropsch synthesis with $\mathrm{Fe} / \mathrm{Cu} / \mathrm{La} / \mathrm{SiO}_{2}$ nano-structured catalyst," Journal of Nanoscience and Nanotechnology, vol. 9, no. 7, pp. 4425-4429, 2009.

[11] A. Nakhaei Pour, M. R. Housaindokht, S. F. Tayyari, and J. Zarkesh, "Fischer-Tropsch synthesis by nano-structured iron catalyst," Journal of Natural Gas Chemistry, vol. 19, no. 3, pp. 284-292, 2010.

[12] A. Nakhaei Pour, M. R. Housaindokht, S. F. Tayyari, and J. Zarkesh, "Effect of nano-particle size on product distribution and kinetic parameters of $\mathrm{Fe} / \mathrm{Cu} / \mathrm{La}$ catalyst in Fischer-Tropsch synthesis," Journal of Natural Gas Chemistry, vol. 19, no. 2, pp. 107-116, 2010.

[13] D. Y. Murzin, "Size-dependent heterogeneous catalytic kinetics," Journal of Molecular Catalysis A, vol. 315, no. 2, pp. 226-230, 2010.

[14] D. Y. Murzin, “Thermodynamic analysis of nanoparticle size effect on catalytic kinetics," Chemical Engineering Science, vol. 64, no. 5, pp. 1046-1052, 2009.

[15] A. Nakhaei Pour, S. M. K. Shahri, H. R. Bozorgzadeh, Y. Zamani, A. Tavasoli, and M. A. Marvast, "Effect of Mg, La and Ca promoters on the structure and catalytic behavior of iron-based catalysts in Fischer-Tropsch synthesis," Applied Catalysis A, vol. 348, no. 2, pp. 201-208, 2008.

[16] A. Nakhaei Pour, Y. Zamani, A. Tavasoli, S. M. K. Shahri, and S. A. Taheri, "Study on products distribution of iron and ironzeolite catalysts in Fischer-Tropsch synthesis," Fuel, vol. 87, no. 10-11, pp. 2004-2012, 2008.

[17] A. Nakhaei Pour, M. R. Housaindokht, S. F. Tayyari, J. Zarkesh, and M. R. Alaei, "Deactivation studies of Fischer-Tropsch synthesis on nano-structured iron catalyst," Journal of Molecular Catalysis A, vol. 330, no. 1-2, pp. 112-120, 2010.

[18] H. I. Chen and H. Y. Chang, "Homogeneous precipitation of cerium dioxide nanoparticles in alcohol/water mixed solvents," Colloids and Surfaces A, vol. 242, pp. 61-69, 2004.

[19] A. Ramirez and L. Sierra, "Simulation of nitrogen sorption processes in materials with cylindrical mesopores: hysteresis as a thermodynamic and connectivity phenomenon," Chemical Engineering Science, vol. 61, no. 13, pp. 4233-4241, 2006.
[20] M. E. Dry, “The Fischer-Tropsch synthesis," in Catalysis: Science and Technology, J. R. Anderson and M. Boudart, Eds., Springer, New York, NY, USA, 1981.

[21] G. P. van der Laan and A. A. C. M. Beenackers, "Kinetics and selectivity of the Fischer-Tropsch synthesis: a literature review," Catalysis Reviews: Science and Engineering, vol. 41, no. 3-4, pp. 255-318, 1999. 

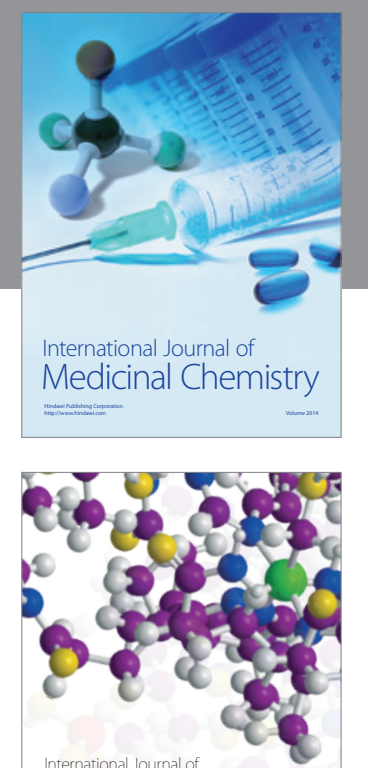

\section{Carbohydrate} Chemistry

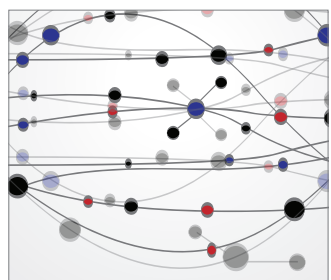

The Scientific World Journal
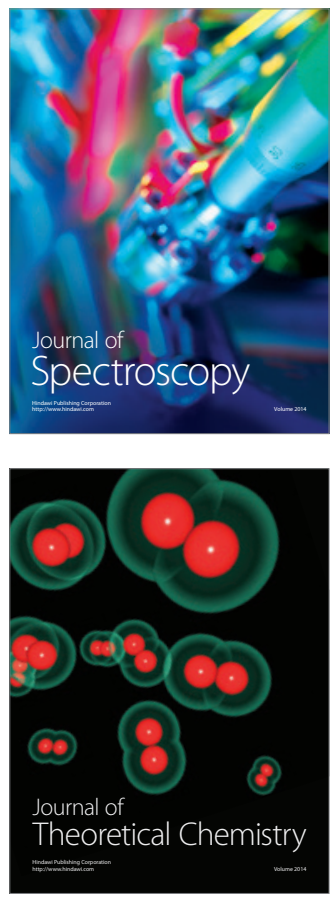
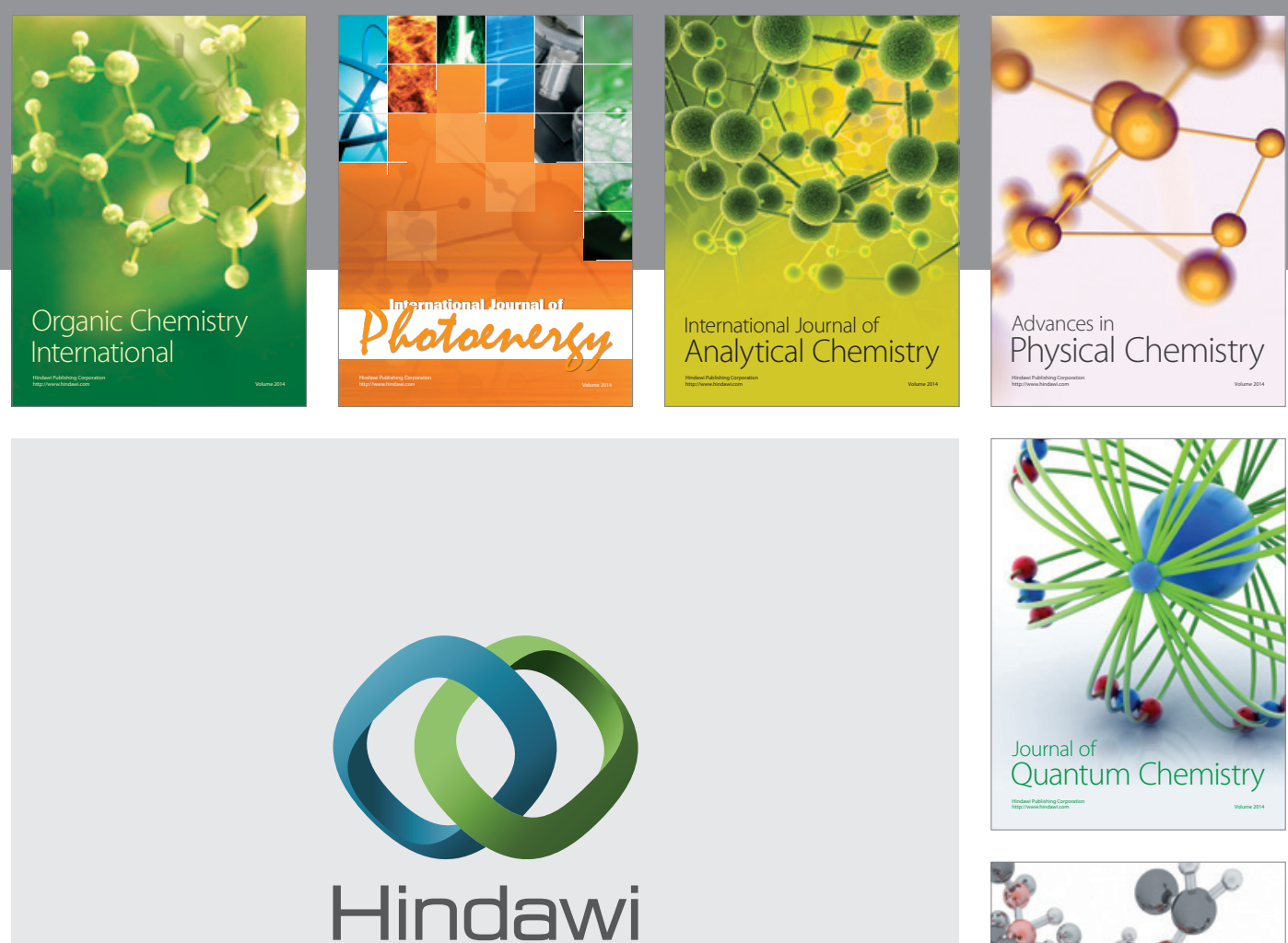

Submit your manuscripts at

http://www.hindawi.com

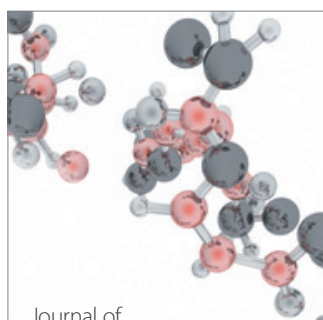

Analytical Methods

in Chemistry

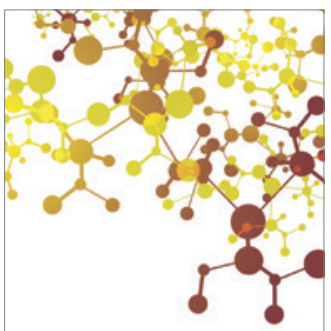

Journal of

Applied Chemistry

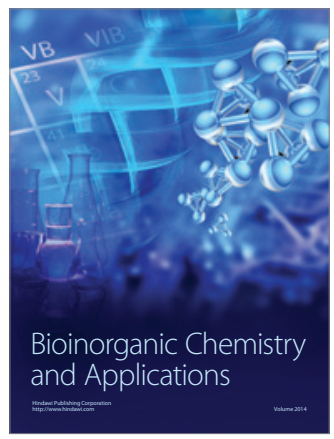

Inorganic Chemistry
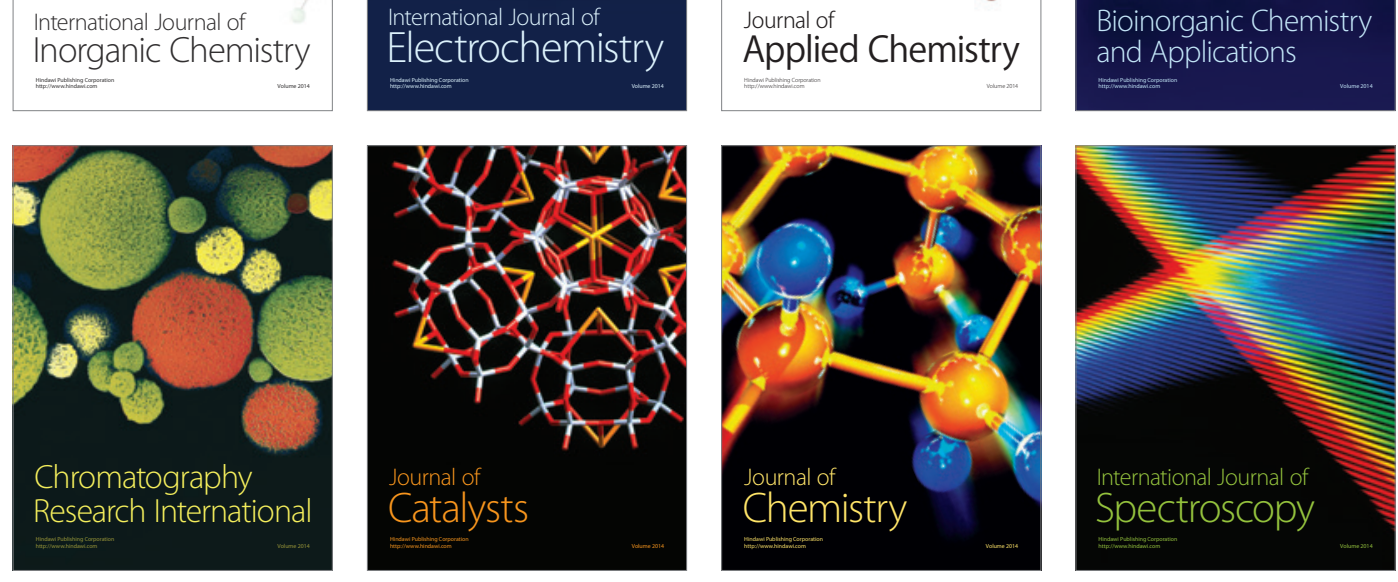